\title{
Modelling of cross-country transport in raster format
}

\section{Marian Rybansky, Alois Hofmann, Martin Hubacek, Vladimir Kovarik \& Vaclav Talhofer}

\section{Environmental Earth Sciences}

ISSN 1866-6280

Environ Earth Sci

DOI 10.1007/s12665-015-4759-y

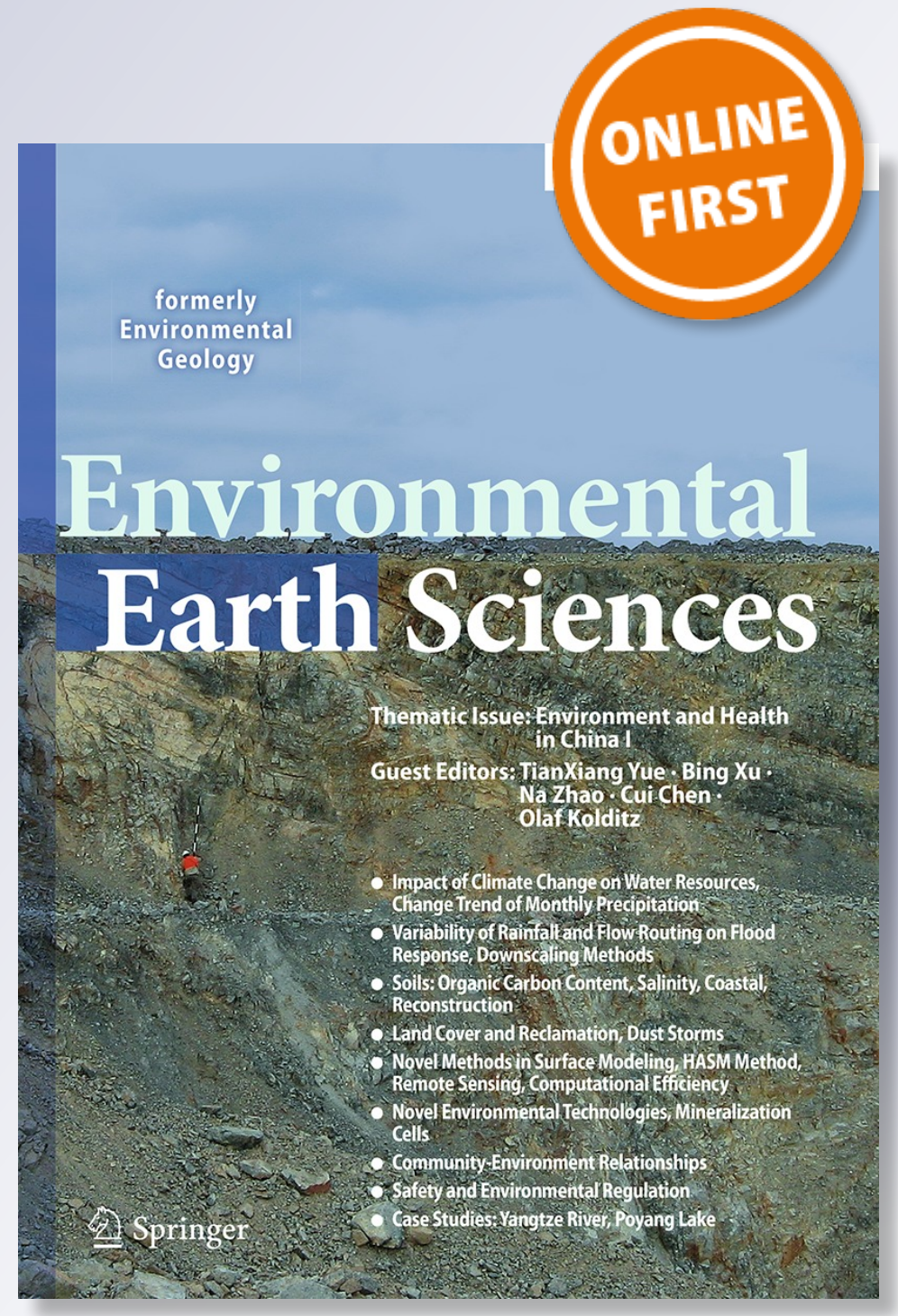

囪 Springer 
Your article is protected by copyright and all rights are held exclusively by SpringerVerlag Berlin Heidelberg. This e-offprint is for personal use only and shall not be selfarchived in electronic repositories. If you wish to self-archive your article, please use the accepted manuscript version for posting on your own website. You may further deposit the accepted manuscript version in any repository, provided it is only made publicly available 12 months after official publication or later and provided acknowledgement is given to the original source of publication and a link is inserted to the published article on Springer's website. The link must be accompanied by the following text: "The final publication is available at link.springer.com". 


\title{
Modelling of cross-country transport in raster format
}

\author{
Marian Rybansky $^{1}$ - Alois Hofmann ${ }^{1} \cdot$ Martin Hubacek $^{1} \cdot$ Vladimir Kovarik $^{1}$ • \\ Vaclav Talhofer ${ }^{1}$
}

Received: 28 May 2015/Accepted: 10 September 2015

(C) Springer-Verlag Berlin Heidelberg 2015

\begin{abstract}
The content of this paper refers to the modelling of the geographic environment impact on the off-road vehicles movement in raster format. The common influences of relief slope, micro-relief forms, soils, vegetation, hydrology, built-up areas, meteorological factors, etc. on the vehicle speed deceleration are calculated. To determine the impact of various geographic environment types on the vehicle movement, many field tests and laboratory analysis were provided using military and rescue vehicles. Modelling principle of cross-country vehicle mobility in raster format is based on the idea that each geographic factor " $F$ " located at given elementary terrain area and affecting vehicle speed has its own value of deceleration coefficient $C, C_{\mathrm{i}} \in\langle 0,1\rangle\left(C_{\mathrm{i}} \in\langle 0 \%, 100 \%\rangle\right)$. The value of this coefficient expresses the fact of how many times (or percent) a certain geographic factor will decelerate the vehicle speed. The final vehicle deceleration is calculated using synthesis of corresponding raster cells in elementary terrain area in which the influences of geographic factors on vehicle speed are constant. The ArcGIS software suite was used for building the cross-country movement (CCM) database and constructing the CCM map. The database, which has been developed for selected vehicles by the Military Geographical Service of the Czech Armed Forces, should serve as a military geographical support tool during the military and civil operations to improve vehicle navigation.
\end{abstract}

Marian Rybansky

marian.rybansky@unob.cz

1 Department of Military Geography and Meteorology, University of Defence in Brno, K-210, Kounicova 65, 66210 Brno, Czech Republic
Keywords Terrain - Geographic factor - Geographic environment · Military vehicle · Transport · Cross-country movement $\cdot$ Military map $\cdot$ Vehicle navigation

\section{Introduction}

The cross-country movement (CCM) of a vehicle usually depends on numerous geographic, meteorological, techni$\mathrm{cal}$, and personnel factors. There is a great difficulty to identify all such factors in the concrete geographic environment and to calculate their influence on a vehicle route and speed across real terrain due to the complicated expressions of the mathematical and physical relationship between vehicle speed and real environmental factors.

For predicting the impact of the geographical environment on the vehicle movement it is necessary to create a virtual geographic environment that represents a generalized picture of the real landscape where the vehicle is moving. A virtual geographic environment (VGE) is a type of workspace for computer-aided geographic experiments (CAGE) and geographic analyses (Lin et al. 2013a).

Modelling of virtual geographic environment or simulation of an object movement in the terrain is addressed by a number of authors (Chen et al. 2013, Lin et al. 2013a, b; Zhang et al. 2015). The real geographic environment in the models is replaced by structural models whose parameters and visualization induce an image of the actual landscape. These models can have form of a map (i.e. 2D models), a digital terrain model (i.e. 3D models), or a dynamic 4D model where the vehicle moves through the terrain. These models are most often used for navigation of vehicles through the road network.

Modelling the movement of vehicles in the open terrain (i.e. off the roads) is more demanding process, where the 
geographic environment is often replaced by raster images of the individual geographic elements and the cost maps are generated for determining the optimal route for vehicles. The issue of an impact of the geographical environment on the movement of vehicles is described for example in (Ahlvin and Haley 1992; Ciobotaru 2009; Cross-country mobility 1997; Procedural guide for preparation of DMA cross-country movement 1993; Rabab 2003; Rybansky 2007, 2009, 2010, 2013; Rybansky and Vala 2009a, b, c, 2010; Spencer 2002; STANAG 3992-AGeoP-1 Terrain Analyses 1990; Stodola and Mazal 2010; Stodola at al. 2010; Taheri et al. 2015; Talhofer et al. 2012; Tate 2006; Vala and Rybansky 2010).

Each of these factors acts on vehicle deceleration individually or collectively with other factors. To resolve these problems, we consider the following two conditions:

- Vehicle route deceleration is based on terrain surface configuration (slope), surface roughness, surface materials (soils), vegetation roughness, etc.

- Vehicle route extension is based on terrain obstacles (mountains, lakes, rivers, settlements, forests, etc.).

The methodology for determining the optimal (i.e. the least-cost) route of a vehicle depends on individual geographic factors. Each such factor contributes to the deceleration of vehicle speed relatively to the maximum speed of a vehicle on the road. The resulting speed of a vehicle in the terrain can be determined by individual decelerating (cost) factors, as part of the particular set of the abovementioned geographic features.

We differentiate between several ways to ascertain the optimal path across the terrain:

- determining the shortest path;

- determining the fastest path;

- determining the cheapest path;

- determining the safest path.

Finding the optimum path can be implemented in vector or raster format. To find the correlation between geographic factors and the resultant speed of the vehicle factor analysis methods were employed and the cross-country movement map was created.

\section{Modelling a cross-country movement (CCM) in raster format}

It is possible for the purpose of cross-country movement modelling to start from the methods presented in (Rybansky 2010) based on the common impingement of particular geographic factors on cross-country movement and manifested by speed reduction (or stopping-down) of movement of vehicle expressed as multiple coefficient of deceleration
" $C$ " or by value $0-100 \%$ with regard to hypothetically determined optimal conditions of movement.

For modelling the impact of the individual geographic factors on the speed of movement of a vehicle the following methods were employed:

- Determining a vehicle speed according to gradients of the relief with the use of traction curves;

- Penetrometric method of determining the effect of soils on the vehicle movement;

- Comparison of technical parameters of the vehicle (fording, swimming) and hydrological parameters of watercourses (depth, flow rate, character of banks);

- Comparison of technical parameters of the vehicle (width, length, minimum turning radius) and structure of forests (stem spacing, stem diameter);

- Determining the effect of meteorological parameters (temperature, precipitation) on selected geographical factors (soils, drainage), etc.

Basic data used for cross-country movement modelling are mostly in vector format and have to be transformed to raster format (see Fig. 1) so that the pixel size at particular layers and their localization are subordinated to layer with the smallest pixel size that the given definition in raster format enables the analysis of elements of the smallest dimensions, i.e. with the highest level of definition of cross-country movement element.

The principle of the respective solution of cross-country movement is based on the fact that we can allocate partial coefficient of vehicle deceleration " $C_{i}$ " to each pixel for a given layer (e.g. for relief slope gradient) and to calculate the resulting values of coefficients of deceleration $C$ for each pixel of resultant-modelled layer (map) of crosscountry movement (vehicle movement deceleration) and theoretically on the basis of the algorithm 1, or more precisely, realistically on the basis of the algorithm 2 (see Fig. 2).

$$
\begin{aligned}
& v_{j}=f\left(v_{\max }, c_{1}, c_{2}, \ldots, c_{n}\right), \quad j=1 \ldots k \\
& v_{j}=v_{\max } \cdot \prod_{i=1}^{n} c_{i}, \quad i=1 \ldots n \\
& \quad j=1 \ldots k ; \text { where } \prod_{i=1}^{n} c_{i}=c_{j} \text { for } i=1, \ldots n
\end{aligned}
$$

Individual coefficients of movement deceleration can be determined (with regard to other geographic factors) relatively independently (e.g. coefficient of deceleration by effect of relief slope gradient $\boldsymbol{C}_{1}$ ) or in dependence (e.g. change of deceleration by effect of soil parameters $\boldsymbol{C}_{\mathbf{3}}$ and drainage $\boldsymbol{C}_{5}$, in dependence on weather conditions $\boldsymbol{C}_{\mathbf{4}}$ ).

Particular deceleration coefficients pertaining to concrete geographical factors can also be dependent on a range of partial factors (e.g. dependence of coefficient of 

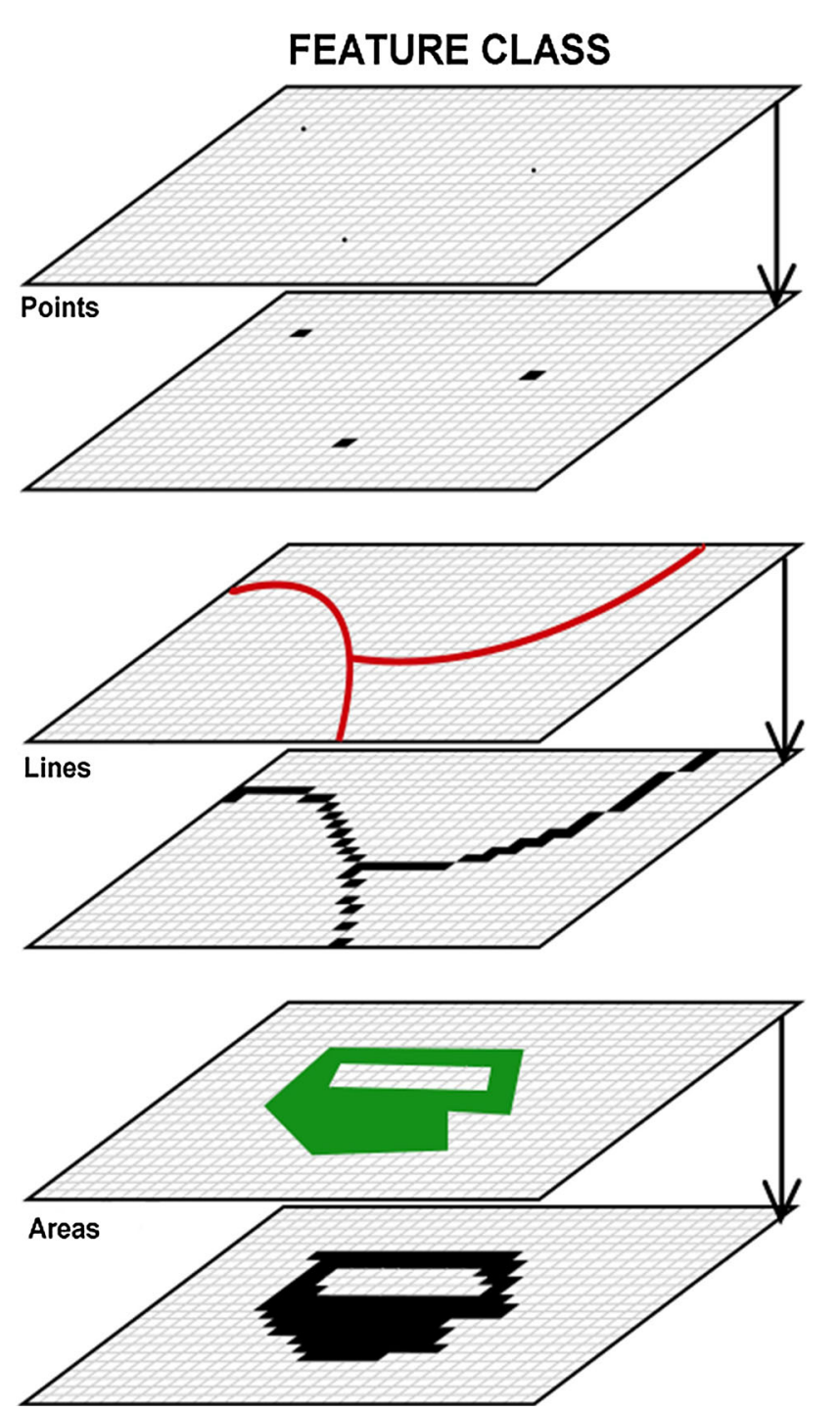

Fig. 1 Transformation of vector layers into raster layers

deceleration by the effect of vegetation $\boldsymbol{C}_{2}$ on tree spacing, stem diameters $\boldsymbol{C}_{\mathbf{2 2}}$, on vehicle parameters $\boldsymbol{C}_{\mathbf{8}}$, etc.).

The calculation is to be made in this manner: each geographic factor $F$ located at a given elementary terrain area and affecting vehicle speed has its own value of deceleration coefficient $C, C_{i} \in\langle 0,1\rangle\left(C_{\mathrm{i}} \in\langle 0 \%, 100 \%\rangle\right)$. The value of this coefficient expresses the fact of how many times (or percent) a certain factor will decelerate a vehicle. Table 1 provides an evaluation of deceleration coefficients pertinent to factors evaluable only by the grade of trafficability: passable, hardly passable, impassable subject, and subject without further characteristics.

The resulting effect of all geographic factors on vehicle deceleration on a given space (pixel) of a route is to be expressed by the algorithm (2).

Individual partial coefficients of vehicle deceleration per effect of particular geographical subjects can be determined according to the method described in (Rybansky 2009), namely:

- terrain relief gradient and micro-relief shapes;

- vegetation;

- soil conditions;

- weather conditions;

- waters (drainage);

- settlements (built-up areas);

- roads.

\section{Relief factor: example of the solution of CCM in raster format}

Relief factors consist of two partial factors:

- vehicle route extension-if the route is uphill (downhill), the vehicle goes a longer distance than the route on flat terrain;

- vehicle speed deceleration factor (vehicle speed decreases with increasing slope of terrain relief).

\section{Vehicle route extension factor}

We must recalculate the real uphill (downhill) route time to the time sequence in flat raster cells using the coefficient $C_{111}$, because all further factors are calculated in plane raster cells. This coefficient can be expressed as the rate of horizontal distance $l$ to real slope distance $l^{\prime}$ (see Fig. 3) and algorithm (3).

$l^{\prime}=l / \cos \alpha^{\circ}, \quad C_{111}=l / l^{\prime}$

When we calculate the horizontal distance $l=1$, we will create the table (see Table 2).

\section{Vehicle speed deceleration factor}

Vehicle speed also decreases with increasing slope of terrain relief (Fig. 4). Using the vehicle tractive diagram (see Fig. 5), we can identify vehicle speed on a slope and calculate the values of the deceleration coefficients $C_{112}$ (see Table 3 ).

Using the values of Fig. 5 and Table 3 we can calculate vehicle speed values affected by the relief factor in raster format (see Fig. 6).

Using the algorithm (3) and Table 1 values we can calculate the vehicle route extension factor in raster format (see Fig. 4).

To check the functionality of the mentioned procedures and respective modelling of cross-country movement in raster format with output in the form of cross-country movement map in scale 1:25,000, the T-72 tank was chosen as the military vehicle (designed primarily for 
Fig. 2 The principle of creation of synthetic layer (map) of cross-country movement

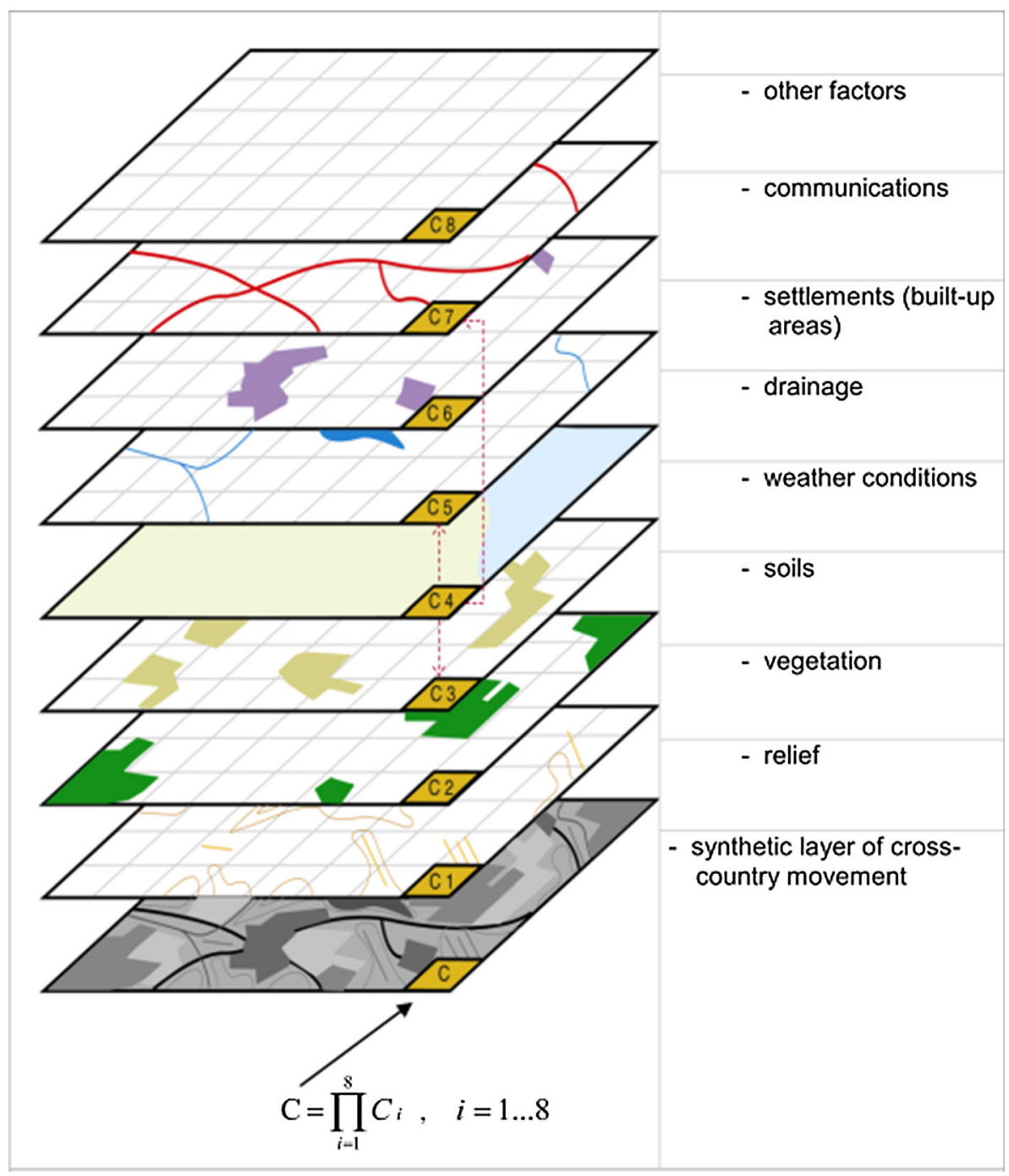

Table 1 Deceleration coefficients

\begin{tabular}{ll}
\hline$F_{i}$ & $C_{\boldsymbol{i}}$ \\
\hline Impassable subject-(NO GO) & 0 \\
Hardly passable subject-(SLOW GO) & 0.5 \\
Passable subject-(GO) & 1 \\
Subject without further characteristics & 1 \\
\hline
\end{tabular}

movement over trackless terrain) and the following method (see also Rybanský 2010):

- selection of suitable area for testing of the creation of the cross-country mobility map of a territory;

- selection of data used;

- preparation of data;

- processing of respective analysis.

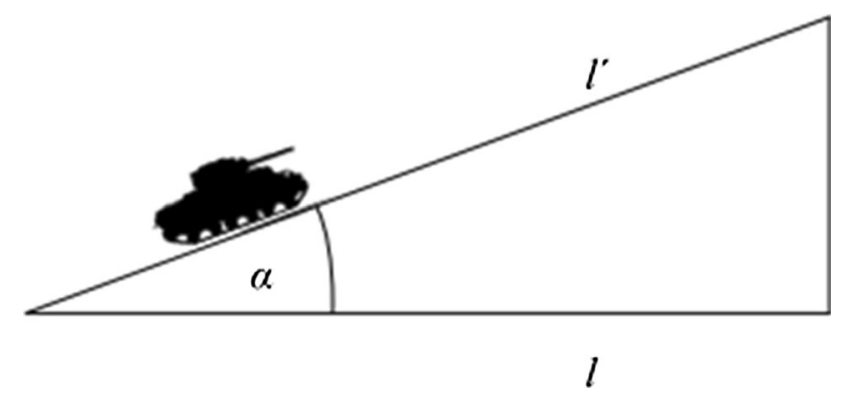

Fig. 3 Vehicle route extension

\section{Results: CCM cost maps and finding the optimal route in terrain}

Using the above-mentioned technology the cross-country movement maps and optimal route were created. 
Table 2 Calculation of $C_{111}$

\begin{tabular}{lllll}
\hline Gradient $\alpha\left(^{\circ}\right)$ & $\cos \alpha^{\circ}$ & $l$ & $l^{\prime}$ & $C_{111}=l / l^{\prime}$ \\
\hline 2.8 & 0.999 & 1 & 1.001 & 0.999 \\
4.0 & 0.998 & 1 & 1.002 & 0.998 \\
5.7 & 0.995 & 1 & 1.005 & 0.995 \\
9.6 & 0.986 & 1 & 1.014 & 0.986 \\
21.0 & 0.934 & 1 & 1.071 & 0.934 \\
27.9 & 0.884 & 1 & 1.131 & 0.884 \\
35.0 & 0.819 & 1 & 1.221 & 0.819 \\
\hline
\end{tabular}

\section{CCM cost map}

The first area depicted on topographic map 1:25,000 M33-93-D-d (Tisnov) was selected on the basis of these principal criteria:

- characteristic forms of terrain from the point of view of cross-country mobility;

- accessibility of data verification.

Particular categorized layers containing coefficient of deceleration of trafficability at each attribute chart are used for elaboration of analysis. To convert vector data into raster data when keeping the attributes, it is necessary to add a new item in the attribute table, containing the product of calculated deceleration coefficient.

Then the calculation according the algorithm (2) is used to compute the effect of all geographic factors on vehicle deceleration. The principle of determination of resulting deceleration coefficient is evident from Fig. 2. If direct values of maximum speed are presented at one of the layers instead of deceleration coefficient (most frequently a relief), the values at the resulting layer also express the maximum possible speed for passing the given section of terrain.

Results of calculations are usable either directly or it is possible to re-classify them, e.g. according to five basic characteristics of cross-country mobility (see Table 4).

Figure 7 shows the synthetic map of cross-country movement map at scale 1:25,000 created on the basis of the methods mentioned in Chapter 2

\section{Optimal route planning}

For finding the shortest, fastest, cheapest or safest path in raster format it is possible to use the Dijkstra algorithm stated in (Rybansky 2010), or commercial software with GIS databases.

For our research and modelling the impact of the individual geographic factors on the speed of movement of a vehicle, the Military training areas Brezina and Libava were used.

The task was solved on the basis of raster analysis and using "fuzzy logic".

It was based on terrain data; in this case the DMU25 model was employed. The DMU25 model, produced by the VGHMUr in Dobruska, was created by digitizing the
Fig. 4 Calculation of vehicle route extension factor in raster format
Slope $\left[{ }^{\circ}\right]$

\begin{tabular}{|c|c|c|c|c|}
\hline 4.0 & 4.0 & 4.0 & 4.0 & 4.0 \\
\hline 9.6 & 9.6 & 9.6 & 9.6 & 9.6 \\
\hline 21.0 & 21.0 & 21.0 & 21.0 & 21.0 \\
\hline 27.9 & 27.9 & 27.9 & 27.9 & 27.9 \\
\hline 35.0 & 35.0 & 35.0 & 35.0 & 35.0 \\
\hline
\end{tabular}

Max. vehicle speed

\begin{tabular}{|l|l|l|l|l|}
\hline 60 & 60 & 60 & 60 & 60 \\
\hline 60 & 60 & 60 & 60 & 60 \\
\hline 60 & 60 & 60 & 60 & 60 \\
\hline 60 & 60 & 60 & 60 & 60 \\
\hline 60 & 60 & 60 & 60 & 60 \\
\hline
\end{tabular}

Route exten. coeff. $l^{\prime} / l$

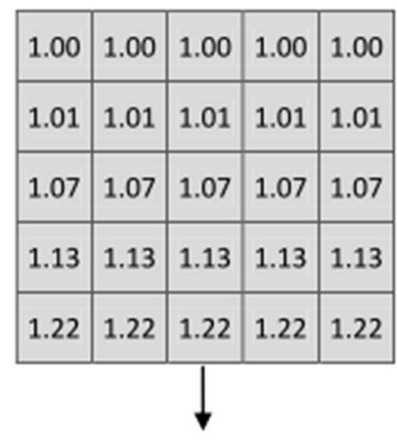

Coefficient $C_{111}=l / l^{\prime}$

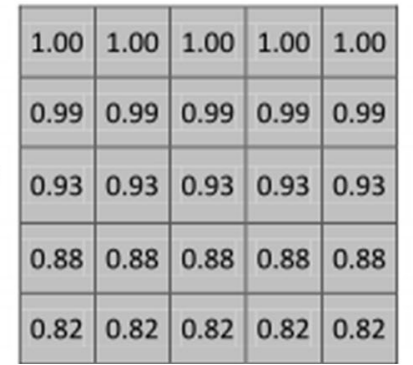


Fig. 5 Tractive diagram for the T-72 tank

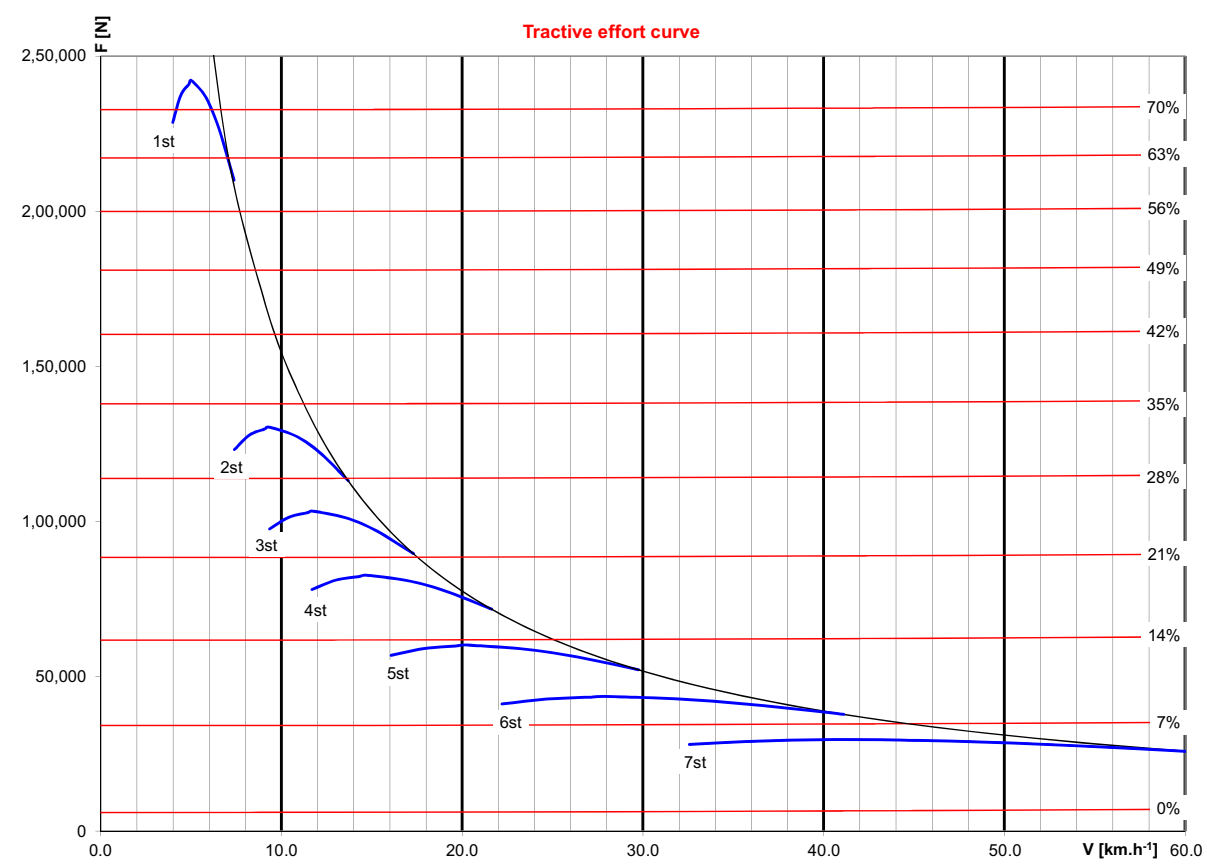

Table 3 Determination of deceleration coefficients using tractive diagram.

\begin{tabular}{lccccccc}
\hline Gradient (\%) & Gradient $\left(^{\circ}\right)$ & $\cos \alpha^{\circ}$ & Speed $\mathrm{km} \mathrm{h}^{-1}$ & $C_{111}=l / l^{\prime}$ & $\begin{array}{l}\text { Deceleration } \\
\text { coefficients } C_{112}\end{array}$ & $\begin{array}{l}\text { Total gradient deceleration } \\
\text { coefficients } C_{11}=C_{111} \times C_{112}\end{array}$ & $\begin{array}{l}\text { Total speed } \\
\mathrm{km} \mathrm{h} \mathrm{h}^{-1}\end{array}$ \\
\hline 3 & 2.8 & 0.999 & 60 & 1.00 & 1.00 & 1.00 & 60 \\
7 & 4.0 & 0.998 & 50 & 1.00 & 0.83 & 0.83 & 50 \\
10 & 5.7 & 0.995 & 40 & 0.99 & 0.67 & 0.67 & 29 \\
17 & 9.6 & 0.986 & 30 & 0.99 & 0.50 & 0.49 & 19 \\
39 & 21.0 & 0.934 & 20 & 0.93 & 0.33 & 0.31 & 9 \\
53 & 27.9 & 0.884 & 10 & 0.88 & 0.17 & 0.15 & 4 \\
70 & 35.0 & 0.819 & 5 & 0.82 & 0.08 & 0.07 & 0 \\
$>70$ & $>35$ & & 0 & & 0.00 & 0.00 & \\
\hline
\end{tabular}

Fig. 6 Recalculated speed to flat 2-D terrain
Max. vehicle speed $\mathrm{km} \cdot \mathrm{h}^{-1}$

\begin{tabular}{|l|l|l|l|l|}
\hline 60 & 60 & 60 & 60 & 60 \\
\hline 60 & 60 & 60 & 60 & 60 \\
\hline 60 & 60 & 60 & 60 & 60 \\
\hline 60 & 60 & 60 & 60 & 60 \\
\hline 60 & 60 & 60 & 60 & 60 \\
\hline
\end{tabular}

Coeff. $C_{11}=C_{111} * C_{112}$

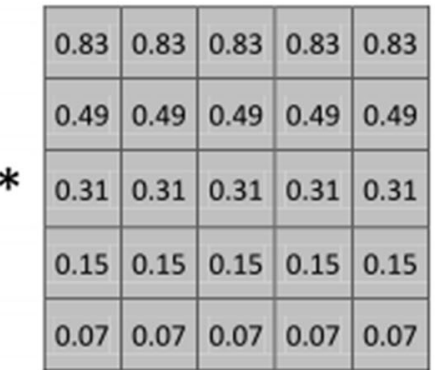

Recalculated speed to flat terrain- $v_{\max } * C_{11}$

\begin{tabular}{|c|c|c|c|c|}
\hline 50 & 50 & 50 & 50 & 50 \\
\hline 29 & 29 & 29 & 29 & 29 \\
\hline 19 & 19 & 19 & 19 & 19 \\
\hline 9 & 9 & 9 & 9 & 9 \\
\hline 4 & 4 & 4 & 4 & 4 \\
\hline
\end{tabular}

analogue map documents and it is a fundamental source for the production of military topographic maps for the Czech Army.
Digital elevation models were employed as another data source for the task. They were created using methods of digital photogrammetry and laser scanning. For a given 
Table 4 Categories of terrain based on cross-country mobility

\begin{tabular}{lll}
\hline Category & $v_{i}(\mathrm{~km} / \mathrm{h})$ & Grade of trafficability of $j$ th section \\
\hline 1 & $>30$ & Passable (go) \\
2 & $>15 \leq 30$ & Passable with restriction (restricted) \\
3 & $>5 \leq 15$ & Hardly passable (slow) \\
4 & $>1.5 \leq 5$ & Very hardly passable (very slow) \\
5 & $\leq 1.5$ & Impassable (no go) \\
\hline
\end{tabular}

task, the models of resolution of 10 and $5 \mathrm{~m}$ were employed as well as the triangular elevation model having the nodes representing significant points selected from a set of scanned data. The third basic data source that was employed was represented by the soil database providing the information related to soil conditions at the test area.

Calculation models in the ESRI ArcGIS were created. The process models are applicable both for different elevation model types and for various means of transportation,
Fig. 7 Cross-Country Movement map at scale $1: 25,000$

\section{Cross-Country Movement map 1:25000}

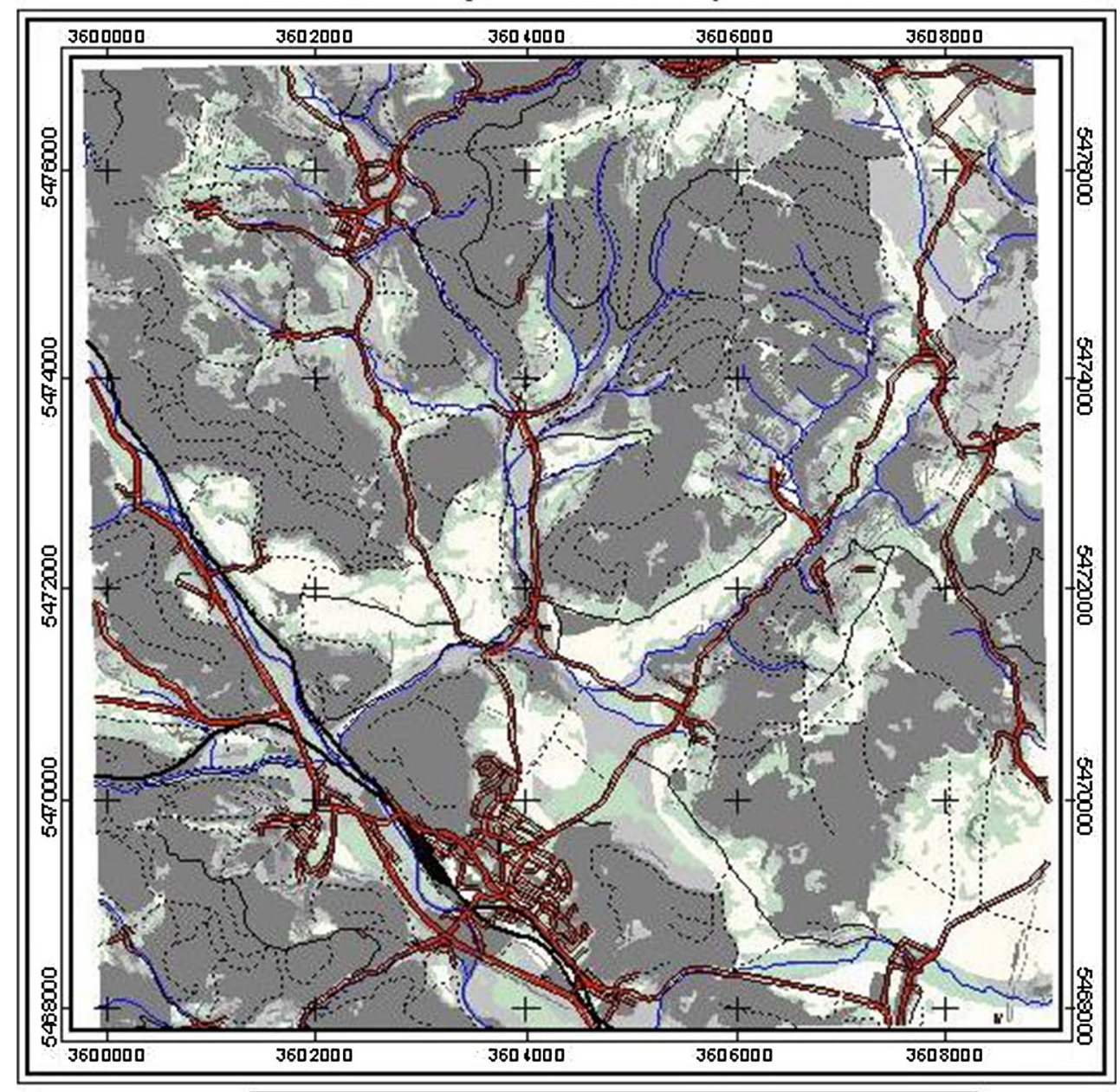

\begin{tabular}{|c|c|c|}
\hline \multirow[t]{8}{*}{ Legend } & & Max. speed (kph) \\
\hline & Railroads & 0 \\
\hline & Primary roads & 0.5 \\
\hline & Secondary & $5 \cdot 10$ \\
\hline & roads & $10 \cdot 20$ \\
\hline & Other roads & $20 \cdot 30$ \\
\hline & Rivers, Streams & $30 \cdot 40$ \\
\hline & & $40 \cdot 50$ \\
\hline
\end{tabular}




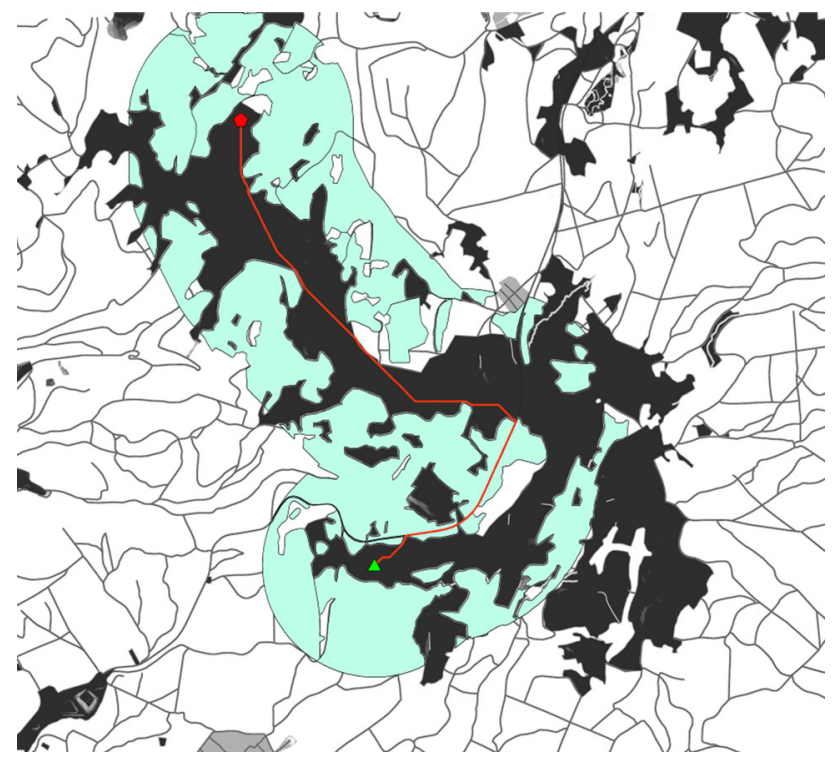

Fig. 8 Displaying the fastest route in 2-D

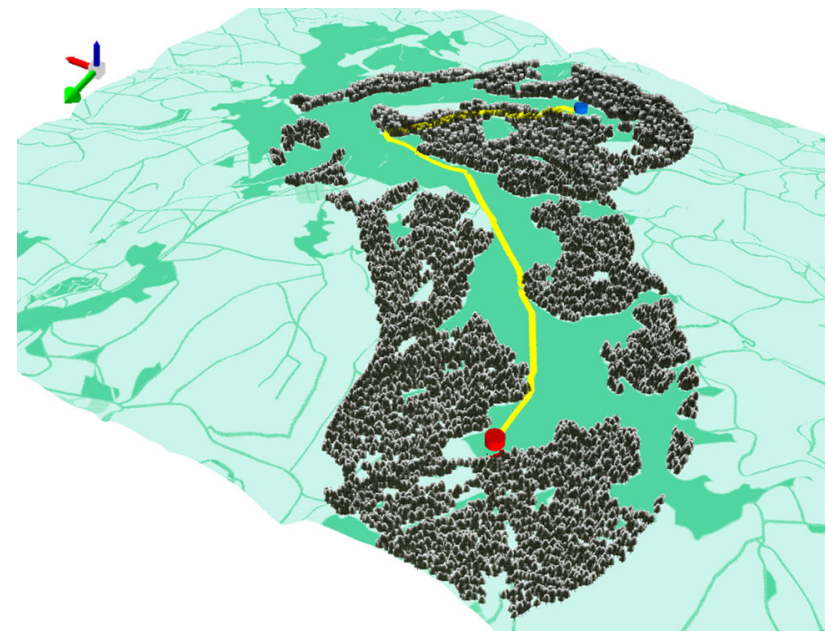

Fig. 9 Displaying the fastest route in 3-D (north-south view)

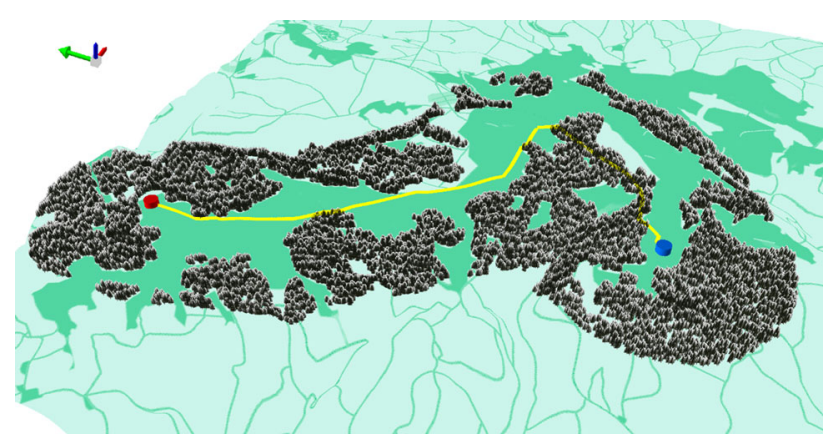

Fig. 10 Displaying the fastest route in 3-D (west-east view)

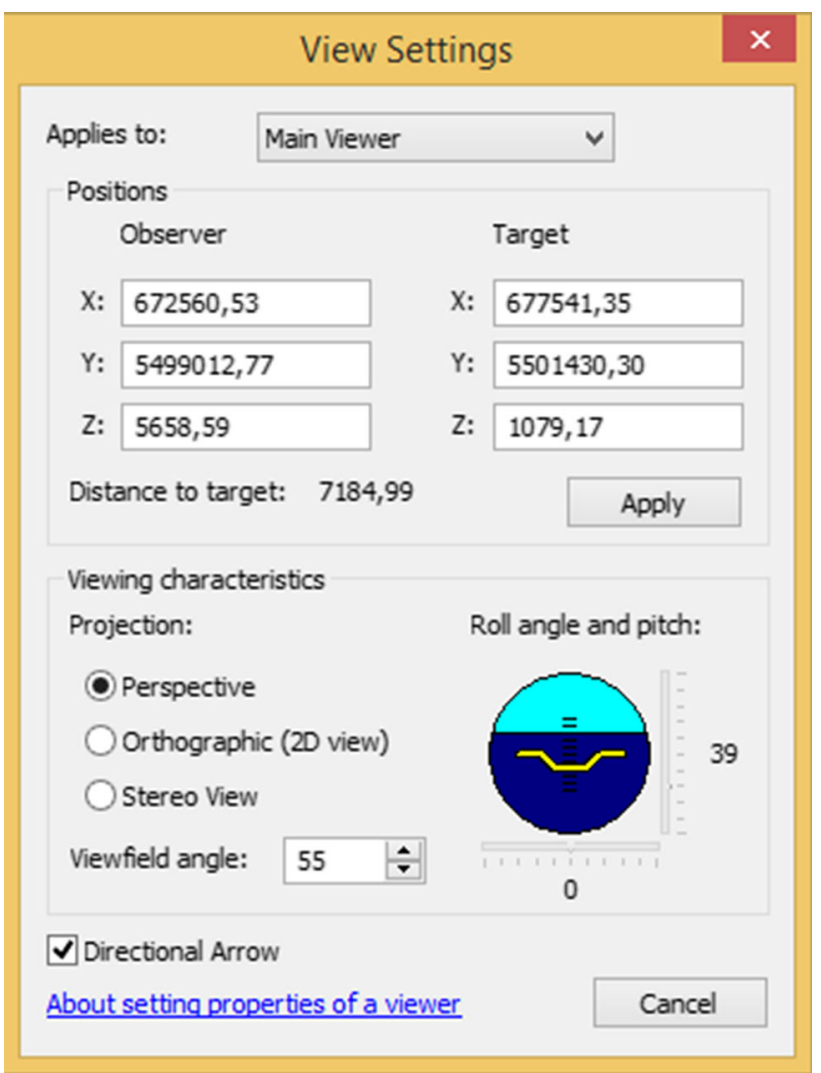

Fig. 11 The example of view settings

such as military wheeled and tracked vehicles that were used for the testing.

Calculations were performed within selected areas on the territory of the Czech Republic. At the beginning, the areas were selected without direct comparison with the real terrain. The next step was to carry out field tests in selected areas with the use of selected means of transportation from the light vehicles to the tracked vehicles, such as the armoured personnel vehicle and the tank.

In the first series of tests the optimal routes were precalculated and these routes were followed by the vehicles in the terrain. The real vehicle routes were recorded using GPS receivers and then compared with the routes calculated.

In the second series of tests the possibilities of movement in a very difficult terrain was tested using similar vehicles. Similar to the first series, each ride was recorded using the GPS receiver. The results will be compared with the cost maps of a given area. Processing of the results is currently under way. Among the first achieved results are the outputs of visualization of a cost map for $10 \mathrm{~m}$ elevation model for a tracked armoured personnel vehicle and calculation of the optimum route.

The effects of terrain slope, obstacles, vegetation, drainage, soils, roads, and built-up areas (in this case 
Fig. 12 Finding of the fastest route from start point to 4 different end points

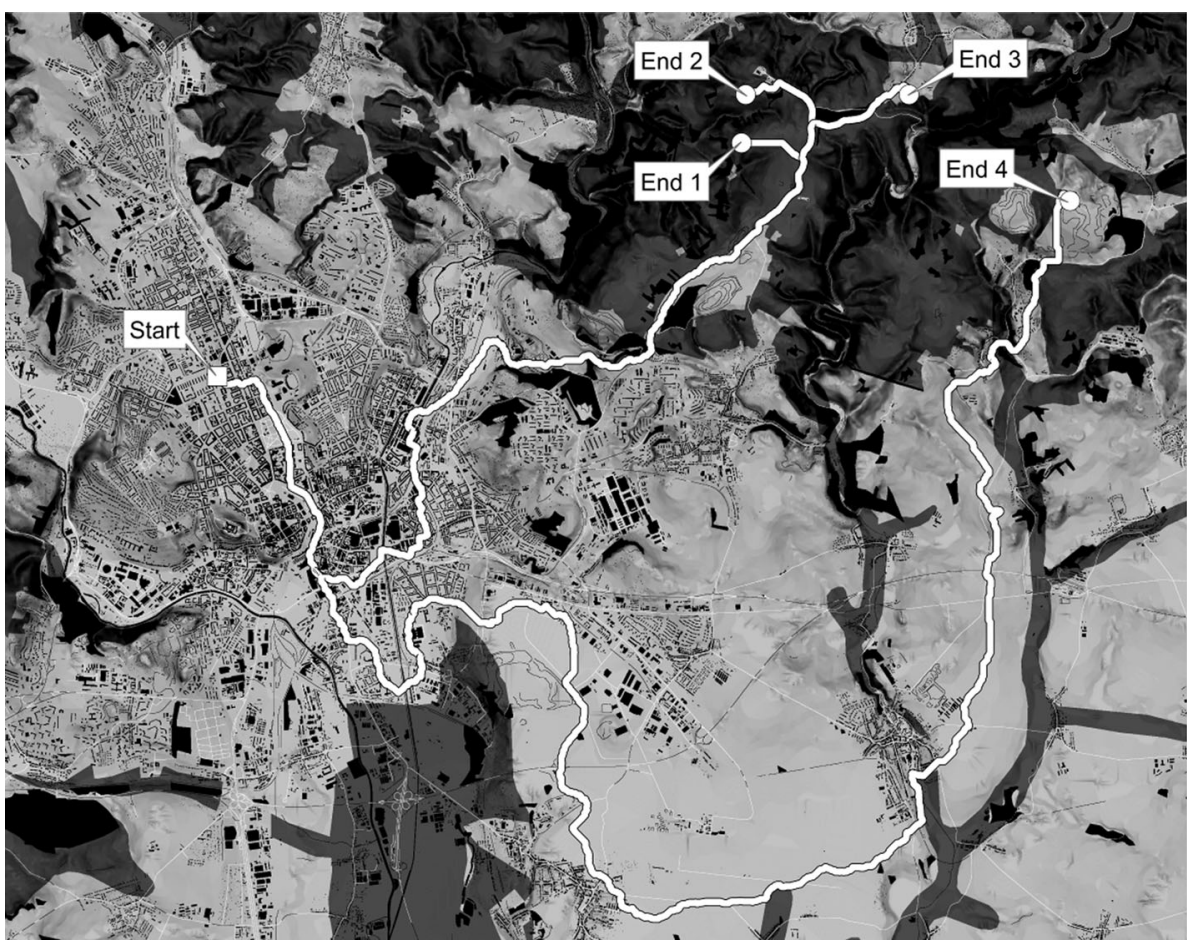

negligible) were incorporated into calculation. The terrain was very rugged particularly in terms of the micro-relief forms, which should be reflected in calculating the cost map using the most detailed elevation model.

Attached visualizations (Figs. 8, 9, 10, 11) show the calculated route in the cost map.

Forest data were created as a point layer using a random number generator and due to a high data volume they were reduced using a $1 \mathrm{~km}$ buffer.

Visualizations are supplemented by the view parameters with the information about locations of an observer and a target. Orientation of a view is present in the image in a form of directions of the axes (the green axis points to the north and it is identical with the axis $y$ in 2D view).

Figure 12 shows the example of finding the fastest route from start point to four different end points in built-up area using the ArcGIS software suite. The value of maximum possible speed $(60 \mathrm{~km} / \mathrm{h})$ was assigned to locations (pixels) representing the roads.

\section{Discussion}

The research results described in this article represent the examples of the use of multidisciplinary knowledge in a domain of geography, morphology, soil science, phytogeography, hydrology, meteorology, and further disciplines that are essential for understanding the overall impact of the geographical environment on mobility of the all-terrain vehicles. The geographic environment where the vehicles were moving was represented by selected parameters of the individual geographic features. Refining these parameters leads on one side to the convergence of the virtual reality models and the real geographic environment, but on the other hand, the time of calculating of the optimum movement routes increases. This could have a negative impact during sudden changes within the geographic environment (i.e. weather conditions, military operations, etc.).

The determination of some uncertain and unstable parameters of the geographical environment (e.g. tree locations, surface changes due to weather conditions) requires collection of data in real time and research activities aimed at refining of the methodology for the effect of geographic environment on movement of vehicles.

On the other hand, the development of new terrain vehicles having a better capability of passing the particular geographic environment will continue.

Acknowledgments This paper is a particular result of the defence research project ZRO K-210 GEORADIANT and Specific research project 2015 at the department K-210 managed by the University of Defence in Brno.

\section{References}

Ahlvin RB, Haley PW (1992) NRMM II users guide, vol 1, 2, 2nd edn. Army Corps of Engineers, Waterways Experiment Station

Chen M, Lin H, Hu M, He L, Zhang Ch (2013) Real geographic scenario based virtual social environment: integrate geography 
with social research. Environ Plan B-Plan Design 40(6):1103-1121

Ciobotaru T (2009) Semi-empiric algorithm for assessment of the vehicle mobility. Leonardo Electron J Pract Technol (15):19-30 (ISSN 1583-1078)

Cross-Country Mobility (1997) Users manual. ESRI, USA

Lin H, Chen M, Guonian L (2013a) Virtual geographic environment: a workspace for computer-aided geographic experiments. Ann Assoc Am Geogr 103(3):465-482

Lin H, Chen M, Lu G, Zhu Q, Gong J, You X, Wen Y, Xu B, Hu M (2013b) Virtual geographic environments (VGEs): a new generation of geographic analysis tool. Earth Sci Rev 126:74-84

Procedural Guide for Preparation of DMA Cross-Country Movement (CCM) Overlays (1993) Defense mapping school. Fort Belvoir, Virginia

Rabab Z (2003) Development of cross country networks for military manoeuvre analysis. MSc Thesis. Hermitage, UK: Royal School of Military Survey

Rybansky M (2007) Effect of the geographic factors on the cross country movement during military operations and the natural disasters. In: International Conference on Military Technologies, University of Defence, Brno (Czech Republic), pp 590-596 (ISBN 978-80-7231-238-2)

Rybansky M (2009) The cross-country movement: the impact and evaluation of geographic factors. Brno, p 113 (ISBN 978-807204-661-4)

Rybansky M (2010) The cross-country movement-modeling. Brno, p 100 (ISBN: 978-80-7204-717-8)

Rybansky M (2013) Modelling of the optimal vehicle route in terrain in emergency situations using GIS data. In: 8th international symposium of the digital earth (ISDE8) 2013, Kuching, Sarawak, Malaysia 2014 IOP conference series: earth environmental science 18012071 doi:10.1088/1755-1315/18/1/012131

Rybansky M, Vala M (2009a) Analysis of relief impact on transport during crisis situations. In: Moravian geographical reports, vol 17, No. 3, pp 36-43 (ISSN 1210-8812)

Rybansky M, Vala M (2009b) Geographic Conditions of Military Transport Using Roads and Terrain. In: ICMT'09-International conference on military technologies 2009, Brno (Czech
Republic), p 9 (ISBN 978-80-7231-649-6 (978-80-7231-648-9 CD))

Rybansky M, Vala M (2009c) Relief Impact on Transport. In: ICMT'09-International conference on military technologies 2009, Brno (Czech Republic), p 9 (ISBN 978-80-7231-649-6 (978-80-7231-648-9 CD))

Rybansky M, Vala M (2010) Vehicle Maneuver through a Vegetation. In: Proceedings of the Joint 9th Asia-Pacific ISTVS Conference, Sapporo, Japan, p 16

Spencer DR (2002) An investigation of improved algorithms for modelling surface interactions between vehicles and terrain. MSc Thesis. Hermitage, UK: Royal School of Military Survey

STANAG 3992-AGeoP-1 Terrain Analyses (1990) Field Manual No. 5-33. Headquarters Department of the Army. Washington, DC

Stodola P, Mazal J (2010) Optimal location and motion of autonomous unmanned ground vehicles. WSEAS Trans Signal Process 6(2):68-77 (ISSN 17905022)

Stodola P, Mazal J, Rybansky M (2010) Dead Reckoning Navigation for Autonomous Unmanned Ground Vehicles in a Real Terrain. In: Proceedings of the Joint 9th Asia-Pacific ISTVS Conference, Sapporo, Japan, p 10

Taheri Sh, Sandu C, Taheri S, Pinto E, Gorsich D (2015) A technical survey on terramechanics models for tire-terrain interaction used in modeling. J Terrramech 57:1-22

Talhofer V, Hošková-Mayerová Š, Hofmann A (2012) Improvement of digital geographic data quality. Int $\mathrm{J}$ Prod Res 50(17):4846-4859 (ISSN 0020-7543)

Tate J (2006) Terrain Analysis for Decision Making. In: Mang R, Häusler B (eds) International Handbook Military Geography. Ministry of Defence, Vienna. ISBN 3-901183-50-7

Vala M, Rybansky M (2010) Relief impact to cross-country movement. In: Proceedings of the Joint 9th Asia-Pacific ISTVS Conference, Sapporo, Japan, p 16

Zhang Ch, Chen M, Jörgensen SE, Lin H, Li R (2015) What's going on about geo-process modeling in virtual geographic environments (VGEs). Ecol Model. doi:10.1016/j.ecolmodel.2015.04.023 